\title{
Debate pedagógico actual: las expresiones políticas de la escuela y la educación
}

Nicanor Moya Rojas* Luis Alberto Baltazar Castañeda** Yéssica Rosario Quispe Espinoza*** Oscar Cencia Crispín $* * * *$

\section{Resumen}

Los escritos que subyacen aquí, procuran fomentar el debate pedagógico en torno a la naturaleza política que tiene y cumple la escuela y la educación, en todo sistema social y económico, desde su constitución y fomento desde la formación económicosocial esclavista, en sustitución de la comunidad primitiva, tanto a nivel nacional como internacional. Por encima de los valiosos aportes que brinda a la formación escolar, ha sido y es un mecanismo de carácter político-económico, que legitima, conserva y reproduce la estructura socio-económica jerarquizada, estratificada y diferenciada, con constatan las investigaciones pedagógicas serias y objetivas, hechas por prestigiosos investigadores connacionales.

\section{Palabras clave:}

\author{
Expresiones \\ políticas, \\ escuela, \\ educación, \\ docencia, \\ Estado.
}

\section{Current pedagogical debate: political expressions of school and education}

\begin{abstract}
The writings behind here, seeking to promote the pedagogical debate on the political nature he has and meets school and education, in all social and economic system since its establishment and promotion from the slaveholding socioeconomic formation, replacing the primitive community, both nationally and internationally. Above the valuable contributions that provides school education, has been and is a mechanism of political and economic, that legitimizes, preserves and reproduces the hierarchical, stratified and differentiated socio- economic structure, with They note the serious educational research and objective, made by prestigious researchers fellow countrymen.
\end{abstract}

\section{Keywords:}

political expressions, school, education, teaching, state.

\footnotetext{
Recibido: 18 de marzo de 2016/Aprobado: 16 de mayo de 2016.

* Doctor en Ciencias de la Educación. Docente de la Facultad de Educación de la Universidad Nacional del Centro del Perú. Correo: nicanorcito_47@hotmail.com.

** Doctor en Psicología Educacional y Tutorial. Docente de la Facultad de Educación de la Universidad Nacional del Centro del Perú.Correo: lbaltazaruncp@gmail.com

*** Mg. en Psicología Educativa.

**** Mg. en Didáctica Universitaria Docente de la Facultad de Educación de la Universidad Nacional del Centro del Perú.
} 


\section{Introducción}

No pocos docentes de Educación Básica Regular, inclusive los del nivel superior (universitario y no universitario), tienen el criterio, errado por cierto, de que la escuela y la educación son mecanismos que están al servicio pleno de la población, sin distinción alguna, diferencia social, menos reflejar determinados intereses económicos, sociales y políticos. Igualmente se sostiene que están libres de toda influencia estatal, teologal y otras instancias culturales. Este es otro craso error, por lo que corresponde a los pedagogos e investigadores sociales aclarar el carácter político que tienen estas variables de estudio y análisis que se efectúa aquí, dando a explicar que desde la desaparición histórica de la comunidad primitiva, fueron y son empleadas para conformar o construir un orden social dado. Esto es lo que siempre ha caracterizado y privilegiado la educación, y lo señala su carácter profundamente político, como razonan Mendo (2006), Capella (2002) y otros. De allí que se exponen los siguientes puntos de vista, naturalmente con el propósito de suscitar el debate y la discusión entre los estudiantes y docentes de todo nivel educativo.

\section{Aspectos histórico-sociales y políticos inherentes a la escuela y la educación}

Presumiblemente debido al hecho que diversos problemas agobian a los hombres y mujeres, niños, adolescentes, jóvenes y adultos, del campo o de la ciudad, no se presta la debida atención, menos el análisis y la explicación de la función que cumplen la escuela y la educación, instituciones seculares y representativas del sistema educativo en la formación de los escolares, inherente a la llamada educación formal, certificadora u oficial, como suele escribir Villavicencio (1996).

Es que en el proceso histórico de su desarrollo, la educación, antes que la de la escuela, estuvo asociada a los aspectos e intereses generales de la comunidad, a las cuestiones laborales de los hombres primitivos y sus relaciones sociales de colaboración, en tanto que no existía aún la propiedad privada sobre los medios de producción, aspecto que dio lugar a la diferenciación y explotación social, la desigualdad entre la ciudad y el campo, la distinción entre el trabajo manual e intelectual. Estos hechos son necesarios tomar en cuenta, valorando las experiencias acumuladas por la humanidad en el curso de su devenir, a fin de contribuir a la dación de nuevas y mejores relaciones sociales y por ende, de la escuela y la educación.

Sin embargo, es de explicar que al desaparecer la histórica y larga comunidad primitiva, y surgir en lugar de ella, la formación económico-social del esclavismo, le cupo a la escuela y la educación cumplir roles inherentes al Estado y la defensa de los intereses económicos y sociales recientemente constituidos, así como preparar a los futuros personajes (funcionarios orgánicos) encargados de dirigir el Estado, la política, el derecho, la familia monogámica y la fuerza laboral necesaria, ad hoc al sistema, naturalmente esclavos dedicados a la actividad laboral, sin derecho alguno.

En el esclavismo, al surgir los grupos y clases dominantes (sacerdotes, jefes, reyes, etc.) la escuela y la educación tienen una nueva y diferente tarea: encargarse de la formación intelectual de los vástagos privilegiados, naturalmente en las instituciones especiales: las 
escuelas, con características propias, según la visión de los dueños del poder, conocimientos singulares y especiales, según sus estilos de vida y organización social imperante. La educación sistemática, inherente a las escuelas se convirtió cada vez más en un privilegio de los privilegiados. En tanto, los esclavos y sus hijos eran instruidos básicamente para el trabajo físico, en condición de explotados, donde los niños se acostumbraban al trabajo manual desde temprano, tal como acontece hoy en gran parte del mundo y del país, en particular.

Tanto en las civilizaciones orientales como occidentales, con la constitución de las clases sociales y la presencia del Estado, la educación y la escuela tuvieron fines definidos y delimitados. Para el caso téngase en cuenta las escuelas hindúes, los centros de instrucción egipcios, las escuelas en China, para las clases dominantes. Aquí, por ejemplo, los niños privilegiados aprendían a leer y escribir complicados jeroglíficos, estudiaban filosofía y moral, obras de escritores y poetas, según los estudios de Konstantinov y otros (1984). En occidente, se tuvo las escuelas militarizadas como en Esparta, en oposición a la escuela estética de los atenienses. La educación estaba controlada por el Estado, y tenía como objetivo hacer de los hijos de los guerreros espartanos, futuros esclavistas, estoicos y endurecidos. El ciudadano espartano, según Abbagnano y Visalberghi (1995) era soldado antes que ciudadano; hasta la edad de veinte años se adiestraba en la vida militar.

Con posterioridad en la formación feudal la escuela y la educación devinieron en mecanismos de dominio económico y social, bajo la orientación de los señores feudales y el clero que controlaban las tierras, los animales y a los campesinos, sometidos a explotación prolongada. El sometimiento de los sectores populares y laborales fue predominante. La iglesia fue el baluarte ideológico de los grupos dominantes. Los clérigos monopolizaban la formación intelectual y la enseñanza tuvo un carácter teológico. En este decurso, la historia y filosofía de la educación universal señalan que el contenido de la educación de niños y adultos estaba orientado por la religión. Lo grave es que se sostenía, erróneamente por cierto, que las personas humildes y pobres deben obedecer a la clase dominante y servir sus intereses, sin chistar de modo alguno, como que en efecto, así aún acontece en nuestra realidad nacional, regional y local, para sorpresa de no pocas personas creyentes y no creyentes.

Al constituirse la formación capitalista, la escuela y la educación adquieren ciertas particularidades según las necesidades e intereses de la naciente social de la burguesía, empeñada en generar nuevas y superiores relaciones sociales y económicas, sobre la base de la producción industrial, el fomento de la ciencia y la tecnología, pero sin dejar de controlary dirigir el Estado liberal.

En lo teórico-pedagógico, surgen nuevas orientaciones, impulsadas por los representantes de la economía productiva, interesada en mundializar la producción capitalista, mercantil, de libre competencia. Aquí se debe aludir a Juan Amos Comenius (1592-1670), quien escribiera Didáctica Magna o Gran Didáctica (1632), en la que se inicia la teoría de la enseñanza, con un criterio activo y práctico, condenando el intelectualismo y el exacerbado espiritualismo. Otro pedagogo importante fue Juan Jacobo Rousseau, nacido en 1712, nacido en Ginebra, Suiza. En sus épocas aurorales se pronunció en contra de la desigualdad social, contra los aristócratas y los haraganes, contra la cultura de la sociedad feudal. Sostuvo que la educación se lograba a partir de 
tres fuentes: la naturaleza, las personas que nos rodean y las causas; pero restringía la educación de los hijos de los trabajadores, quienes deben educarse en la vida misma. Expresando su simpatía por la naciente burguesía liberal, demandó desarrollar las llamadas "propiedades innatas del espíritu humano", cuestionando la enseñanza escolástica, verbal y formalista, al decir de García (1984).

Posteriormente, en la etapa contemporánea, con el surgimiento del capitalismo monopolista, la escuela y la educación se implementan mejor para garantizar la economía mundial, mayor producción y productividad, acentuar la explotación de la fuerza laboral de los trabajadores, la exacerbación de la nacionalización, del militarismo y procuran justificar la eternidad e inmutabilidad del régimen capitalista. A fines del siglo XIX e inicios del XX surgen diversas teorías pedagógicas, como las de Jorge Kerchnsteiner, alemán, propulsor de la "educación cívica" a fin de enseñar a los niños a obedecer incondicionalmente al Estado, y de la "escuela del trabajo", para formar obreros y jóvenes técnicamente calificados y educados políticamente de acuerdo con sus intereses. Negaba la necesidad de educar según la visión materialista del mundo, rechazando al movimiento socialista. Cuestionaba la escuela popular, que la "escuela del trabajo" debe brindar un mínimo de conocimientos y un máximo de habilidades, hábitos y amor al trabajo manual. Luego, Eduardo Thorndike, John Dewey, William James y otros difunden la filosofía pragmatista, reconociendo como criterio de la verdad la utilidad y el instrumentalismo ("instrumento de acción)" (Konstantinov, y otros, 1984).

\section{Naturaleza de la escuela y la educación}

La constitución y desarrollo de la filosofía, en su versión científica, a partir de mediados del siglo XIX y a lo largo del XX, continuando en el XXI, permitió explicar que la escuela y la educación no se fundan en el supuesto de la "abstracta naturaleza humana", dada de manera determinada y siempre equilibrada y que estén por encima de los intereses sociales, sino que son, precisamente, instrumentos de manejo, control y fortalecimiento del poder en las clases propietarias. Es decir la escuela y la educación, por intermedio de funcionarios y docentes ad hoc, propagan sistemáticamente posturas, creencias, actitudes, valores e ideologías coherentes con el sistema económico-social imperante, coherentes con los que disponen el aparato del Estado. Rivera (1987) sostiene que en contextos socio-políticos capitalistas, devienen en valiosos medios de legitimación, conservación y reproducción de la estructura socio-económica jerarquizada, estratificada y diferencial. Lo llamativo es que aquí los hombres, trabajadores mayormente, se convierten en "mercancías", productos o elementos cosificados, pero necesarios para garantizar los objetivos del sistema imperante.

Este es un asunto serio que los pedagogos y educadores no deben dejar de analizar y explicar, si es que realmente se precian de ser tales, tanto para tener un conocimiento real y objetivo sobre la naturaleza de la escuela y la educación, como para superar las creencias ingenuas, ilusas, faltos de una epistemología científica, como es común observar en el medio, incluso en docentes universitarios "científicos e investigadores", que adolecen de una adecuada formación filosófica, pedagógica y epistemológica, denotando a la vez ser víctimas de la despolitización y desideologización implementados por el burdo pragmatismo que se diera en el país, desde inicios de la década del 90 del 
siglo pasado, el cual ha motivado que la educación se convierta en una simple mercancía, debido al amparo del D.L.882-1996, que propicia hasta hoy la privatización educativa en todos sus niveles, con la malformación, la cosificación y la alienación de millones de seres humanos, hombres y mujeres.

Para revertir esta anómala situación escolar y educativa, menos mal, importantes investigaciones procesadas por Freire (1989), Rivera (1998), Mendo (2006), Rivero (2007), Pease y Romero (2013) entre otros, han servido y sirven para demostrar que ambas categorías pedagógicas, se organizan en función a las exigencias sociales, económicas y políticas predominantes. Así, Mendo escribe:

...desde el punto de vista de su relación con el orden social la educación ha sido vista, desde sus orígenes, como uno de los elementos necesarios para conformar o construir un orden social dado. Esto es lo que siempre ha caracterizado y privilegiado la educación y lo que señala su carácter profundamente político. Toda educación tiene que ver fundamentalmente con la formación de las conciencias y, a través de éstas, con la construcción de un determinado tipo de sociedad. (Mendo, p. 22)

A tono con esta fundamentación, Capella (2002) recurriendo a Salazar Bondy (1972), igualmente afirma que la educación es inevitablemente política, es irrenunciablemente política, como no podía ni puede ser de otra manera. Pero esta influencia política, casi siempre ha estado en función de los intereses dominantes.

Para demostrar la naturaleza política que tiene la educación, por ejemplo, se tiene la posición político-educativa de uno de los intelectuales peruanos, como el de Alejandro O. Deustua (1937), pensador y político, oriundo del actual distrito de Ahuac, provincia de Chupaca, quien en la década del 30 , del siglo XX, sin rubor alguno insertara en una de sus obras importantes, La Cultura Nacional, la situación de la educación y la escuela en relación a los indígenas, paisanos suyos:

Qué influencia podrá tener sobre esos seres, que sólo poseen la forma humana las escuelas primarias más elementales? ¿para qué aprenderán a leer, escribir y contar, la geografía y la historia y tantas otras cosas, los que no son personas todavía, los que no saber vivir como personas, los que no han llegado a establecer una diferencia profunda con los animales ni tener ese sentimiento de dignidad humana principio de toda cultura' ¿por qué habrían de ser más felices, con esas ideas, que los más no podrán aplicar en su vida extraña a la civilización y de que algunos podrían hacer uso contra sus semejantes? Sólo un concepto intelectualista de civilización puede concebir la felicidad en esas condiciones. (Deustua, p. 344)

De lo mencionado, se colige que la escuela y la educación no son simples entes creados por el Estado para atender las demandas educativas de la población, menos satisfacer las amplias necesidades y expectativas de millones de seres deseosos de buscary lograr una superación social y personal. Menos puedan acceder a una educación de calidad, pertinencia y equidad, como debiera de ser, a pesar que formalmente se exponga en sendas políticas educativas dadas por el Estado: como la Ley de Reforma Educativa No. 
19326 (1972), la Ley General de Educación No. 28044 (2003), la Ley de Reforma Magisterial No. 29944 (2012), etc.

Ninguna de estas normas legislativas de la educación ha podido resolver el problema nacional, el atraso económico y productivo, tampoco superar la escasa y baja calidad educativa y los aprendizajes mediocres, menos afrontar la difícil situación profesional, laboral, social, remunerativa y cultural de los miles de educadores connacionales que sempiternamente viven explotados y marginados, sin que ningún régimen, por más democrático que se reclame haya podido emprender estos retos. Entonces el eslogan de que la educación es la actividad "vital, decisiva y esencial para el progreso social y humano", deviene mayormente en una simple declaración demagógica de políticos y gobernantes de turno. Rivero (2007) razona que "el maestro lo es todo y se le atribuyen muchas funciones sociales; $y$, en contraste, se la califica como una profesión de bajo prestigio social, lo que se expresa en reducidos salarios (con la idea, equivocada por cierto, de que cualquier persona puede ejercerla, aun sin una formación específica para ello) y en la falta de estímulos para que los maestros se actualicen, mejoren su labor e innoven" (Rivero, p. 88). Pero, esta situación no es algo gratuita, casual e improvisada; todo lo contrario, está debidamente concertada y responde a las políticas educativas emprendidas por los regímenes neoliberales que controlan el aparato del Estado y los intereses de los organismos financieros internacionales, como el Banco Mundial, el Fondo Monetario Internacional, entre otros.

\section{Funciones de la escuela y la educación}

Es indiscutible que la escuela y la educación han brindado y brindan grandes contribuciones al desarrollo humano, desde la dación de diversos conocimientos, valores, actitudes, costumbres, pasando por la capacitación de los aspectos inherentes al hombre, para que éste se convierta en un ser productivo a nivel personal, grupal y profesional con un elevado nivel de pensamiento. Es más, la educación tiene que ver con las distintas maneras de actuar, de relacionarse, de interpretar, de hacer aportes al desarrollo social, etc., como sostienen Moya y Cencia (2015). Sin embargo, conformarse con estas funciones escolares y educativas, sería tomar en cuenta solamente una parte del problema, en tanto que se abstrae lo esencial del fenómeno educativo. Por ello es un imperativo sostener que la escuela y la educación adecuadamente organizadas por el Estado, a través de sus diversas instancias u organismos cumplen las siguientes funciones:

1‥ Reproduce el sistema estructural económico-social, desigual que impera en el país. De modo que la educación por más esfuerzo y sacrificio que ejerza los docentes y otros agentes educativos no pueden resolver este asunto de naturaleza económica y política.

2‥ Es indudable que la escuela y la educación transmiten valores, actitudes, creencias, costumbres, y estilos de vida, de trabajo, pero coherentes con los fundamentos filosóficos y pedagógicos imperantes.

3‥ A través de la dación de un buen presupuesto, apoyo tecnológico, curricular y docentes capacitados y dación de políticas educativas ad hoc al sistema prepara a los hombres y mujeres que han de dirigir el Estado, porque así lo demanda y requiere el sistema social y político. 
4․ El Estado, con el respaldo de la iglesia, los medios de información y organizaciones políticas fomentan la privatización de la escuela y la educación, disponiendo para ello de leyes como el D.L 882, 1996, convirtiendo estas actividades como un servicio, antes que como un derecho, al que deben acceder millones de escolares y personas interesadas en educarse.

5‥ Contradictoriamente, se diseña e implementa para los sectores populares o a los hijos de éstos, apenas una elemental educación, tradicional y rutinaria como sostienen los pedagogos colombianos De Zubiría (1995), con la cual es sumamente difícil superar el estado de atraso económico-social de Latinoamérica, y de modo especial del Perú, donde impera una escuela y una educación limitada, sin poder modificar la condición económica agro-extractiva del país.

\section{Opciones a tomar, a modo de conclusiones}

Ante la problemática expuesta, a manera de mantener el debate pedagógico, es necesario afirmar que los docentes, discentes y demás actores sociales partícipes del desarrollo escolar y educativo efectúen la investigación no solamente científica, sino igualmente pedagógica y educativa, para comprender la naturaleza aquí explicitada. Pero, no quedarse simplemente en este reconocimiento, sino hacer de la escuela y la educación medios reales y posibles del desarrollo humano, que diferencia de los animales, seres inferiores en su proceso evolutivo en relación a la especie humana. Es más, siendo un proceso humano, intencional, intercomunicativo posibilite la realización, con mayor plenitud, la personalización y la socialización del hombre al decir de Fermoso (1997), siempre y cuando se dé en mejores condiciones económico-sociales, obviamente distinta al actual sistema capitalista, en su versión neoliberal predominante a nivel mundial y nacional, como explican Moya y Cencia (2015).

Se debe revalorar los planteamientos de pedagogos y educadores peruanos, estudiosos de la educación en concordancia con la realidad nacional, como Mariátegui, quien analizara La educación nacional al interior del proceso cultural y económico, considerándola como el medio fundamental para la constitución de una nueva sociedad y la generación de un "alma matinal" que superase al ser decadente que encarnaba el "alma crepuscular", según los escritos de Burga y otros (2013).

Comprender que la escuela y la educación, por si solas, no es ni puede ser la única solución de los problemas nacionales y humanos, sino van dirigidas por una acertada política económica, social y una clara filosofía, que refleja los intereses mayoritarios. Es en este contexto que debe reafirmarse que la educación es uno de los caminos para la realización humana, pues la dota de sólidos conocimientos científicos, de principios éticos y estéticos, y de valores. Esta perspectiva, como reconocen Burga y otros (2013), en términos educativos, ha recogido -muchas veces contra viento y marea- la formidable búsqueda de millones de peruanas y peruanos que pugnan por educarse y formarse humanamente. Esta formación exige un vínculo claro con la realidad nacional, que incluya la multiplicidad cultural que posee el Perú.

Igualmente no puede ni debe soslayarse los ideales de Tobón (2014) de exigirse la formación humana integral de los estudiantes y, dentro de éstos, la preparación de 
personas con competencias para actuar con idoneidad en diversos contextos, tomando como base la construcción del proyecto ético de vida, el aprender a emprender y la vivencia cultural, considerando las dinámicas sociales y económicas, superando los criterios discriminatorios de concebir que los hijos de los trabajadores deben a lo sumo acceder a una educación elemental y básica, sin mayor trascendencia social, económica y política.

Referencias Bibliográficas

Burga, M. y otros (2013) Presentación al libro Dilemas educativos ante la diversidad. Siglos $X X-X X I$, de Trapnell y Zabala. Colección Pensamiento Educativo Peruano. Volumen 14. Lima: Derrama Magisterial.

Capella, J. (2002) Política Educativa. Aportes a la política educativa peruana. Lima: Impresos \& Diseños, S.A.C. Editores.

Deustua, A. (1937) La Cultura Nacional. Lima: Imprenta Americana.

Fermoso, P. (1997) Teoría de la educación. México: Editorial Trillas.

García, G. (1984) La concepción marxista sobre la escuela y la educación. México: Editorial Grijalbo, S.A.

Konstantinov, N., Medinskih, E. y Shabaeva, M. (1984) Historia de la Pedagogía. Buenos Aires: Editorial Cartago.

Mendo, J. (2006) Entre la Utopía y la Vida. Ensayos sobre Filosofía, Educación y Sociedad. Lima: Fondo Editorial del Pedagógico San Marcos.

Moya, N. y Cencia, O. (2015) Filosofía, Política y Educación. Fundamentos para el desarrollo nacional. Huancayo: Grapex Perú S.R.L.

Rivera, J. (1987) Educación, dominación y tecnología educativa. Serie: Educación y liberación. Lima: ATEI Editores.

Rivero, J. (2007) Educación, Docencia y Clase Política en el Perú. Lima: Impresión y Cuadernación: Asociación Gráfica Educativa Tarea.

Tobón, S. (2014) Formación integral y competencias. Pensamiento complejo, currículo, didáctica y evaluación. Bogotá: ECOE Ediciones.

Villavicencio, A. (1996) En torno al concepto de educación. Lima. 